\title{
Research of the milling rotor work with high damping capacity
}

\begin{abstract}
The results of a study of the process of grinding wood by a milling rotor with high damping capacity of the case. A decrease in the dynamic torque and the total cutting force is obtained. The dependence of the dynamic torque on the feed quantity on the knife during the milling of pine wood is established.
\end{abstract}

Keywords: milling, rotor, damping capacity, impact load, cutting force
Volume 2 Issue 3 - 2018

\author{
Bulatasov Edward O, Popov Valery RN, Hanin \\ Viktor RN \\ Department of Food Biotechnology, Orenburg State University, \\ Orenburg, Russia
}

Correspondence: Bulatasov Edward O, Department of Food Biotechnology, Orenburg State University, Orenburg, Russia, Email eduard190319@mail.ru

Received: May 28, 2018 | Published: June 07, 2018

\section{Introduction}

A variety of types of raw materials used in proceedings, based on mechanical wood processing, characterized by high hardness and sample size, which firstly requires cutting operations for sorting parts and the size of the feed stock directly to the grinding, and secondly, the process creates grinding high dynamic loads, acting as the cutting tool, and the entire cutting mechanism as a whole. Milling machines for the crushing of wood have a number of advantages over the other. Firstly, they are high-performance voditelny allow cut chips of large thickness and a relatively low strength of interaction with the wood cutting tool, and, secondly, processed wood of different lengths, eliminating the need for pre-cutting wood to length. ${ }^{1,2}$ When milling materials produces intermittent cutting. ${ }^{3}$ Intermittent cutting is a process in which at certain intervals constituting seconds or fractions of a second stroke of the tool (cutting chips) alternateswith idle. Cyclical unloading and loading of contact surfaces during interrupted cutting affect the resistance of the cutting tool. ${ }^{3}$ And the cyclical mechanical stress is a major cause of lowering the resistance of the cutting tool due to impact phenomena occurring at the initial moment of interaction with a workpiece and the main source of driving oscillations (vibrations). ${ }^{4,5}$ This circumstance substantially determines operability of the cutting tool and in particular manufactured using the carbide and mineral ceramics. ${ }^{4}$ Reduced shock and vibration by reducing the cutting speed. It leads to a substantial loss of productivity and makes use of a cutting tool of hard metal impractical. ${ }^{4}$ The strain energy waves during shock loading of the cutting tool can intensively absorbed dissipative boundaries, e.g., providing constructive conditions of friction elements on the contact surfaces of the cutting tool designs can achieve effective damping of shock loads. ${ }^{6,7}$ But in most cases, in surface contact designs compounds of the cutting tool still and their damping action slightly. ${ }^{8}$ More effective ways to reduce shock and vibration based on the absorption of vibration energy by the use of vysokodempfiruyuschih materials and structures that provide shock damping. ${ }^{4}$ The use of elastic damping elements in the construction of the cutting tool by allowing cutting force reduction to reduce the impact force during insertion of the tooth, and thereby reduce the amplitude of oscillations due to the fact that the elastic damping element, having a low rigidity, can absorb the impact energy. ${ }^{8-15}$ AT communication from outlined there necessity design design milling rotor, allowing highly effectively dampen shocks. This design was developed in view of certain characteristics of the analysis structures milling rotors and features Process grinding Wood data type cutting tool from characteristic shock oads. As a result, designed and manufactured construction milling rotor provided on Figure 1. The design of the milling rotor comprising: an integral body, whose parts are movable on the cylindrical surface of the conjugate in two directions - direction of rotation of the rotor, and - against; damping elements in the construction of the housing, the rigidity of which determines the magnitude of said movement depending on the magnitude of force generated at the cutting edge of the knife. As a result, the impact of the knife against the wood blade together with the movable housing part is displaced in a direction reverse to the rotation of the rotor by a certain amount and compresses the damping elements, which reduces the action of shock loads on the cutting tool, and hence the cutting force, due to the fact that the damper compression elements absorb part of the kinetic impact energy, and displacement of one part of the body upon impact on other cutters to reduce the rigidity as the striking body, and consequently reduce the force of impact. Experimental studies carried out on the installation, the construction of which is shown in, ${ }^{16}$ under the following conditions: cutting speed $v=13 \mathrm{~m} / \mathrm{s}$; cutting circle diameter $\mathrm{d}=178 \mathrm{~mm}$; Cutting width $12 \mathrm{~mm}$; Rear angle $\alpha=30^{\circ}$; cutting angle $\delta=70^{\circ}$; the angle of inclination of the cutting edge $\lambda=3^{\circ}$; sharp knives; knife material R18 speed steel (GOST 19265-73); infeed knife $\mathrm{Sz}=1,5 \ldots$ 7,5mm; wood species Pine (density $\rho 12=0,40 \mathrm{~g} / \mathrm{cm}^{3}$ ); wood humidity $\mathrm{W}=18 \%$. Cutting was performed by applying torque the working shaft and the workpiece on the cutting knife. Thus measured dynamic torque of the output shaft depending on the feed to the knife. Received experimental data allowed establishing a connection between the dynamic torque moment $\mathrm{M}$ and feeding to the knife and $\mathrm{Sz}$ to construct the graph of this function (Figure 2). 


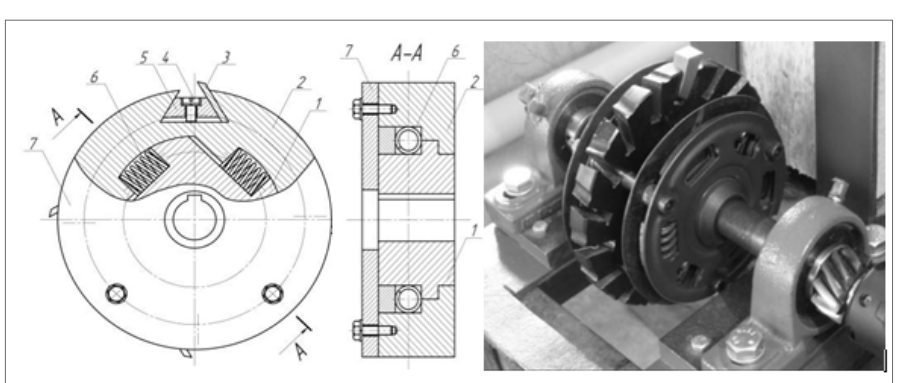

Figure I Drawing of the structure and a photo milling rotor. I:a rotor housing; 2: the toolholder; 3: cutting tool; 4: screw; 5:Wedge; 6: a spring steel; 7: drive.

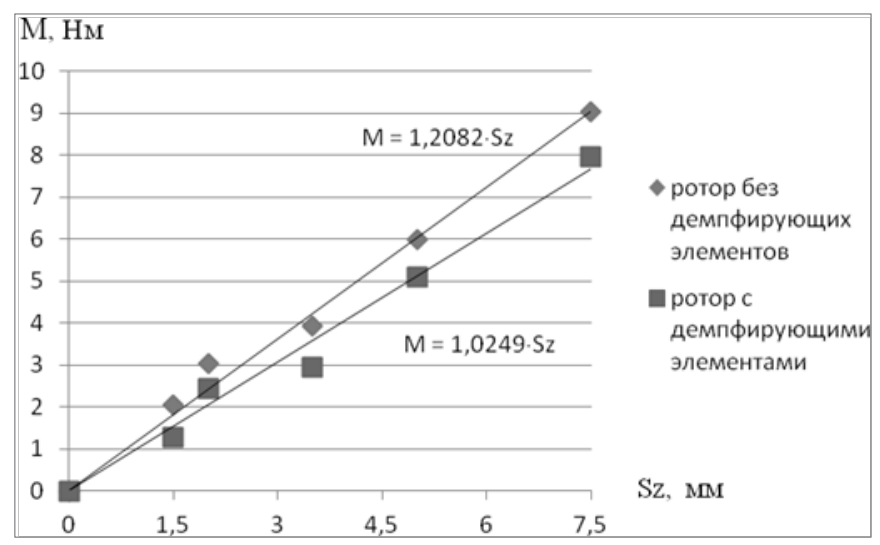

Figure $\mathbf{2}$ The dependence of dynamic torque by feeding to the knife milling pine wood along the grain milling rotor and new standard design.

\section{Analysis of the results revealed}

1. Total dynamically increase torque by increasing the feed to the knife.

2. Decrease dynamic torque and accordingly the total cutting force at the cutter rotor new construction: in a few cases when cutting thick chips $15 \mathrm{~mm}-7 \%, 3,5 \mathrm{~mm}$ thick-up to $30 \%, 7,5 \mathrm{~mm}$ thick-Up to $12 \%$. Thus, by applying design of the milling rotor damping elements of different hardness can change its damping capacity that allows to create the best working conditions for cutting tools and machinery in general, depending on the physico-mechanical properties of the material work over an. Developed milling rotor arrangement can effectively reduce the effects of impact loads encountered during crushing of wood, and can be used in the construction of the rotary cutter and shredder milling wood type.

\section{Conflict of interest}

Author declares that there is no conflict of interest.

\section{References}

1. Churilin AA. New for cutting wood. The forest industry. 1967;122.

2. Schwartzman GM. Generously DA Manufacture of chipboard. The forest industry. 1987;319.

3. Bobrov VF. Fundamentals of metal cutting theory. Engineering. 1975;344.

4. Zhirkov AA. Increase in the durability of cutters controlled impulse action with interrupted cuts. Disscand tehn Sciences Orel. 2005;153.

5. Kremleva LV. Development of a dynamic model for the design of the cutting process of the cutting tool and the machining parameters during face milling. Disscand tehn Nauka Moscow. 1998;132.

6. Panovko JG. Fundamentals of Applied theory of vibrations and shock. University of Technology. 1990; 272.

7. Structural dampening tion in fixed joints/Acad. Latvian Academy of Sciences. SSR. Inst mechanics and automation; NG Kalinin, YA Lebedev, VI Lebedev et al. ed. Corr. Academy of Sciences of Latvia. SSR prof. Dr. tehn. YG Sciences Panovko. Riga: Publishing House of the Acad. Latvian Academy of Sciences. SSR, 1960;170c.

8. Zharkov IG. Vibrations during processing blade tool. Engineering Leningrad Dep set. 1986;184.

9. Arshinov VA, Alekseev GA. Metal cutting and cutting tools. $3^{\text {rd }}$ ed. Engineering. 1975;440.

10. Breev SV. Improving the quality of the treated surface with a cylindrical milling based on studies of stress-deformed state of chip area. Dis cand tehn Sciences Komsomolsk on Amur. 2011;151.

11. Krivoukhov VA, Voronov AA. The high-frequency vibration tool for turning. Oborongiz. 1956; 77.

12. Kumabe D. Vibration cutting. Engineering. 1985;424.

13. Loladze TN. The strength and wear resistance of the cutting tool. Engineering. 1982;320.

14. Andreev GS. Beat in intermittent cutting of metals. Engineering Bulletin. 1971;3:65-67.

15. Andreev GS. Improving cutting tool performance with occasional cutting. Machines and tools. 1979;11:31-33.

16. Bulatasov EO, Popov VP, Hanin VP. Impact of the shape of the cutting edge and the front surface of the blade at power rates chipping. Forest $\mathrm{Zh}$ Math Executive Proc Institutions. 2017;2:149-159.

\section{Acknowledgements}

None. 